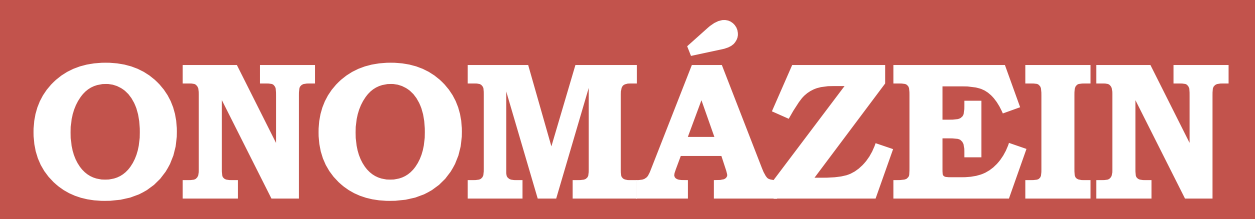

Revista de lingüística, filología y traducción
PONTIFICIA UNIVERSIDAD CATÓLICA DE CHILE FACULTAD DE LETRAS

\title{
La interrelación entre lingüística y filosofía en Sincronía, diacronía e historia de Eugenio Coseriu*
}

The Interrelation between Linguistics

and Philosophy in Sincronía, diacronía e historia by Eugenio Coseriu

\section{Araceli López Serena \\ Universidad de Sevilla \\ España}

\section{(C) $($ ii) $\ominus$}

Araceli López Serena: Departamento de Lengua Española, Lingüística y Teoría de la Literatura, Facultad de Filología, Universidad de Sevilla, España. | Correo electrónico: cheilop@us.es 


\section{Resumen}

La obra científica de Eugenio Coseriu se vertebra en torno a dos "obsesiones" fundamentales: la defensa de la indisolubilidad de las dimensiones lingüística y filosófica de la teorización sobre el lenguaje y la obstinación por el establecimiento de diferenciaciones sistemáticas. En relación con ambas fijaciones, este trabajo muestra en qué medida Sincronía, diacronía e historia no es, únicamente, un mero tratado sobre el problema del cambio lingüístico, sino que constituye, más bien, la obra clave para desentrañar los principios epistemológicos que vertebran el edificio filosófico-científico de la teoría lingüística coseriana. A tal fin, se analiza en qué medida el prurito coseriano por la diferenciación hunde sus raíces en la filosofía y se examina qué aspectos del pensamiento lingüístico de Coseriu, qué procedimientos de argumentación y qué categorizaciones y conceptos esenciales de su teorización lingüística tienen su origen en cuestiones de naturaleza filosófica, vinculadas, esencialmente, no con la filosofía del lenguaje, sino con la filosofía de la lingüística.

Palabras clave: Eugenio Coseriu; Sincronía, diacronía e historia; epistemología lingüística; teoría del cambio lingüístico; ciencias humanas.

* El desarrollo de este trabajo se enmarcó inicialmente en el proyecto de investigación "Tradiciones discursivas, tradiciones idiomáticas y unidades de análisis del discurso en la historia del español moderno" (FFI2014-51826-P), financiado por el Ministerio de Economía y Competitividad del Gobierno de España. Debido a los tiempos de producción, su publicación ha pasado a formar parte, finalmente, del proyecto I+D "Tradicionalidad discursiva e idiomática, sintaxis del discurso, traducción y cambio lingüístico en la historia del español moderno: prosa (pre-)periodística/ ensayística y literaria" (TradHisMod 2) (referencia PGC2018-097823-B-I00), financiado por el Ministerio de Ciencia, Innovación y Universidades del Gobierno de España. Las reflexiones que en él se vierten se gestaron durante la preparación de una conferencia plenaria que tuve la oportunidad de dictar en el congreso internacional Actualidad y Futuro del Pensamiento de Eugenio Coseriu, celebrado a principios de agosto de 2017 en las Universidades Pontificia Católica del Perú y del Pacífico (ambas en Lima). Me gustaría agradecer a los Dres. Jorge Wiesse y Carlos Garatea su invitación para pronunciar dicha conferencia, que me sirvió de acicate para la profundización en la estrecha interrelación que, en el pensamiento de Eugenio Coseriu, se da entre Lingüística y Filosofía. 


\section{Abstract}

Eugenio Coseriu's scientific work revolves around two main "obsessions": defending the indissolubility of the linguistic and philosophical dimensions of theorization on language; and the insistence on establishing systematic differentiations. With regard to both fixations, this work shows the extent to which Sincronía, diacronía e historia is much more than a simple treatise about the problem of linguistic change; it must rather be described as the key work when it comes to unraveling the principles that underpin the philosophical-scientific edifice of Coserian linguistic theory. For this purpose, our analysis has focused on the degree to which Coseriu's interest in differentiation finds its roots in philosophy, additionally examining what aspects of Coseriu's linguistic thinking, what argumentation procedures and what essential categorizations and concepts of his linguistic theorization originate in issues of a philosophical nature mainly associated not with philosophy of language, but with philosophy of Linguistics.

Keywords: Eugenio Coseriu; Sincronía, diacronía e historia; Philosophy of Linguistics; linguistic change theory; human sciences. 


\section{Introducción}

Una de las características idiosincrásicas del pensamiento científico de Eugenio Coseriu, que sin embargo rara vez se subraya ${ }^{1}$, es el carácter de ámbito de encuentro entre filosofía y lingüística que ofrece, en tantas ocasiones, la obra del maestro rumano. Para Coseriu, lo lingüístico y lo filosófico están estrechamente interconectados, y ello hasta tal punto que, en Sincronía, diacronía e historia, la obra en torno a la que se vertebran las reflexiones contenidas en las presentes páginas, llegó a afirmar, contra quienes reivindicaban "la autonomía de la lingüística con respecto a la filosofía", que "tal autonomía es imposible, y el pretenderla es en sí mismo un contrasentido" (Coseriu, 19883: 199). En ese mismo libro, abundaba en su argumentación en los siguientes términos:

muchos lingüistas, celosos de una autonomía impropia, consideran con desconfianza a la filosofía, que es la ciencia misma de los principios. Debido a este estado [...] de lamentable aislamiento, en la lingüística se siguen planteando como "actuales" viejos problemas ya resueltos hace mucho tiempo, o eliminados como inconsistentes, por la filosofía o por las demás ciencias del hombre (Coseriu, 19883: 217, n. 63; la cursiva es mía).

A este respecto, la postura del propio Coseriu está en las antípodas de la de los lingüistas a los que califica como "celosos de una autonomía impropia" frente a la filosofía. Como él mismo señala, en sus trabajos lingüísticos afloran continuamente lo que — de momento² - podríamos denominar, con él, "problemas de filosofía del lenguaje", que, según él mismo señala, "se encuentran tratados en varios [de sus] trabajos[:] en particular, en Forma y sustancia, en Logicismo y antilogicismo, en "Determinación y entorno» y en Sincronía, diacronía e historia..." (Coseriu, 1968 [1977]: 342).

Hay, en efecto, en Coseriu, una evidente propensión a fundamentar constantemente su labor de teorización lingüística en aspectos que no pertenecen, en puridad, ni a la teoría del lenguaje ni a la lingüística general3 sino que forman parte, más bien, del campo de la filosofía del lenguaje. Pero, además, la inclinación de Coseriu por la filosofía se manifiesta de manera recu-

1 Hay, desde luego, algunas excepciones, como el trabajo de López Serena (2009), los artículos que Gerda Haßler o Jörn Albrecht publicaron en el volumen Eugenio Coseriu aujour d'hui. Linguistique et philosophie du langage, editado por Christoph Gérard y Régis Missire en 2015, o la introducción a la compilación de estudios dedicados por E. Coseriu a la filosofía del lenguaje que coordinó, en 2007, Cristian Bota (cf. Coseriu, 2007b), y que apareció, también en francés, en la revista Texto!, en 2008, con un título prácticamente idéntico: Eugenio Coseriu: linguistique et philosophie du langage. Pero se trata, justamente, de excepciones. Cf. también Rodríguez (2016).

2 Más adelante se abogará, sin embargo, por la necesidad de distinguir, dentro de lo que Coseriu Ilama filosofía del lenguaje, entre filosofía del lenguaje propiamente dicha y filosofía de la lingüística.

3 Sobre la distinción entre teoría del lenguaje y lingüística general, cf. infra, en § 3 , las figuras 1 y 2. 
rrente también en su preocupación por la legitimidad científica de nuestra disciplina, una preocupación que es objeto ya no de la filosofía del lenguaje, sino de la filosofía de la lingüística, y que pone de relieve su vindicación de que, "en el conocer, lo que importa es la cualidad científica del conocimiento, aparte si nos conduce a un sí o a un no" (Coseriu, 1953 [1977]: 262; la cursiva es mía).

Así las cosas, tres son los ámbitos a los que, cuando se analiza la interrelación entre lingüística y filosofía en el quehacer científico coseriano, resulta ineludible atender: la lingüística, la filosofía del lenguaje y la filosofía de la lingüística. Por lo que respecta a los dos últimos, la filosofía del lenguaje y la filosofía de la lingüística, y como ya se ha apuntado anteriormente ${ }^{4}$, me interesa subrayar la diferencia, para evitar que, como demasiado a menudo ocurre, se consideren filosofías equivalentes. Por ello, frente al frecuente uso indistinto, que se observa en ocasiones (cf., p. ej., Barber [ed.], 2003) de los marbetes filosofía de la lingüística, filosofía del lenguaje y filosofía lingüística, creo que resulta más indicado emplear de manera diferenciada:

(i) Filosofía del lenguaje para hacer referencia a la rama de la filosofía que se ocupa, en relación con el problema del significado, de las relaciones entre el lenguaje, el conocimiento y la realidad, y se pregunta, por ejemplo, si es o no posible diferenciar claramente entre estos tres dominios (el lenguaje, el conocimiento y la realidad), además de indagar en la naturaleza del propio lenguaje como tal.

(ii) Filosofía lingüística para denominar a la corriente filosófica que, inspirada en la filosofía de Wittgenstein, dio lugar al conocido giro lingüístico en la filosofía anglosajona (cf. Carr, 1994: 3027).

(iii) Y, por último, filosofía DE LA lingüística para aludir a toda reflexión metateórica, epistemológica —o metodológica, si se quiere- que tenga como objeto de análisis propio los fundamentos de la lingüística como disciplina científica5

De hecho, entiendo que, al defender esta diferenciación, soy absolutamente consecuente con el compromiso de Coseriu con las categorizaciones precisas y rigurosas. Y es que, no en vano, junto a la estrecha relación que, en el pensamiento de este autor, observamos entre lingüística y filosofía, la segunda constante más clara y general de las aportaciones coserianas en los tres ámbitos mencionados (la lingüística, la filosofía del lenguaje y la filosofía

4 Cf. supra n. 2.

5 Sobre la filosofía de la lingüística, se pueden ver los trabajos de Itkonen (1970, 1974, 1975, 1976a, 1976b, 1976c, 1978, 1980, 1981a, 1981b, 1983, 1984, 1993, 1996, 1997, 1999a, 1999b, 2002a, 2002b, 2002c, 2003, 2003 [2008], Wunderlich (ed.) (1976), Oesterreicher (1979), Bunge (1983), Fernández Pérez (1984, 1985, 1986), Bernardo (1995, 1999), Carr (1990, 1994, 2006, 2006²), Martí (1993, 1998), López Serena (2003, 2007, 2008, 2009, 2011, 2014a, 2014b, 2016, 2019), Jiménez Ruiz (2006). Sobre filosofía de la ciencia en general, cf. Bunge (1980), Chalmers (1982), Estany (1993), Díez y Moulines (1999), Echeverría (1999), Rosenberg (2000) y Diéguez (2005), entre otros. 
de la lingüística), una constante que representa, indudablemente, otra de las características más emblemáticas del lingüista rumano, es su obsesión por distinguir; por distinguir, por ejemplo, en el ámbito de la lingüística, los aspectos que conciernen al sistema de aquellos que atañen a la norma (cf. Coseriu, 1952 [1973]) $)^{6}$, o los niveles universal, histórico y actual del lenguaje (Coseriu, 1956-57, 1988, 1990, 2007a), y, en correlación con ellos, Ios saberes elocucional, idiomático y discursivo, y los conceptos de designación, significado y sentido, o de congruencia, corrección y adecuación (conjunto de triparticiones que Haßler, 2015, bautiza como trinidades coserianas). Y en el terreno de las interrelaciones entre lingüística y filosofía, la preocupación por diferenciar entre teoría del lenguaje y lingüística general, por un lado, así como entre filosofía del lenguaje y lingüística (pero no, como hemos visto, hasta el punto de desear considerarlas autónomas), por otro lado.

Más difícil en este sentido es, sin embargo, encontrar con nitidez, en las palabras de este autor, la distinción entre filosofía del lenguaje y filosofía de la lingüística que se acaba de propugnar aquí, aunque hay, al menos, un artículo en que sí parece apostar con rotundidad por ella. Concretamente, esto ocurre cuando, en un trabajo publicado en italiano, al hilo de la institución de la diferenciación entre interdisciplinariedad genérica e interdisciplinariedad específica, Coseriu afirma que la primera de las dos (la interdisciplinariedad genérica) es aqueIla que se establece entre cualquier disciplina y la filosofía, y ello bajo dos formas diversas: como filosofía del objeto de la disciplina (es decir, como reflexión ontológica, la propia de la filosofía del lenguaje) y como filosofía de la ciencia o epistemología: "L'interdisciplinarità generica è quella che si riscontra fra ogni disciplina e la filosofia, quest'ultima sotto due forme diverse: como filosofia dell'oggetto della disciplina in questione e come filosofia della scienza (epistemologia)" (Coseriu, 1980: 44).

\section{Objetivos}

De lo dicho hasta ahora se desprende que la obra de Coseriu se erige sobre el pilar de dos inquietudes u "obsesiones" fundamentales: por una parte, la indisolubilidad, en su acercamiento al lenguaje, entre la dimensión lingüística y la dimensión filosófica de la teorización, y, por otra, la obstinación del lingüista rumano por la diferenciación. En relación tanto con lo primero como con lo segundo, el objetivo de este trabajo - que persigue, en última instancia, mostrar en qué medida Sincronía, diacronía e historia no es, únicamente, tal como reza el subtítulo de esta monografía, un mero tratado sobre el problema del cambio lingüístico, sino que constituye una obra fundamental para desentrañar los principios epistemológicos que

6 Sobre el concepto coseriano de norma, interesan especialmente Méndez García de Paredes (1999), Koch (1988), López Serena (2015) y Kabatek (2019), entre otros. 
vertebran el edificio filosófico-científico de la teoría lingüística coseriana en su totalidad7_es múltiple. Para empezar (\$ 3.1), se impone comprobar si la evidente fijación de Coseriu por la distinción se reflejaba, en sus consideraciones filosófico-lingüísticas, con la misma intensidad con que lo hacía en su obra puramente lingüística o lingüística propiamente dicha. A continuación (\$ 3.2), resulta obligado indagar en el hecho de en qué medida esta obsesión coseriana por la diferenciación procedía — o no- de su contacto con la filosofía. Y, por último (§ 3.3), parece pertinente examinar qué aspectos del pensamiento lingüístico de Coseriu, qué procedimientos de argumentación y qué categorizaciones y conceptos esenciales de su teorización lingüística tenían su origen en cuestiones de naturaleza filosófica, especialmente en lo que respecta al ámbito de la filosofía de la lingüística. A este último fin me serviré (en § 4), sobre todo, de Sincronía, diacronía e historia, una de las obras que ya hemos visto que el propio Coseriu menciona cuando nos pone sobre aviso acerca de en cuáles de sus trabajos se abordan cuestiones que él considera de filosofía del lenguaje, y que, hasta donde sé, no ha sido nunca objeto de un análisis epistemológico.

\section{El prurito por la distinción en la obra de Eugenio Coseriu}

\subsection{La presencia de las distinciones coserianas en el ámbito de la filosofía del lenguaje}

El propósito de atestiguar la presencia del afán coseriano por distinguir, que tan característico resulta en su lingüística, también en sus trabajos de orientación filosófica no requiere demasiados esfuerzos. Basta con abrir las primeras páginas de su Geschichte der Sprachphilosophie... ${ }^{8}$ para encontrar, en el capítulo de introducción que encabezaba la edición original del primer tomo - un capítulo que, lamentablemente, Albrecht eliminó en su reciente edición de 2003-, una denuncia sobre la situación de confusión y también de abandono o desamparo ${ }^{10}$ en que, en el momento en que Coseriu escribía, estaba, en opinión de este au-

7 A ello apunta también el hecho de que esta es la única obra de Coseriu de la que se hace eco Esa Itkonen, uno de los mejores filósofos de la lingüística contemporáneos (cf., p. ej., Itkonen, 2011, 2013-14).

8 La Historia de la filosofía del lenguaje desde la Antigüedad a nuestros días, que se publicó, en alemán, gracias a la labor de Rudolf Windisch y Gunter Narr, en 1969 y 1972, como resultado de la edición de los apuntes dictados en dos asignaturas homónimas que Coseriu había impartido en los semestres de invierno de 1968/69 y 1970/71 en la Universidad de Tubinga, y de la que no existe aún versión española.

9 Eladjetivo verworren, que emplea Coseriu, equivalea 'caótico', ‘confuso', 'desordenado', 'enmarañado'.

10 La palabra que utiliza en alemán, y que destaco, como el participio verworren, al que se refiere la nota anterior, en cursiva en la cita siguiente, es hilflos. 
tor, sumida la filosofía del lenguaje: "Die Forschungslage im Bereich der Sprachphilosophie erweist sich bei einer näheren Betrachtung als verworren und hilflos" (Coseriu, 1969 [1975²]: 1; la cursiva es mía) ${ }^{11}$.

A resultas de ello, y habida cuenta de su querencia por la cognitio clara et distincta, se imponía, naturalmente, proporcionar a los estudiantes un marco conceptual general desde el que definir la filosofía del lenguaje como disciplina diferenciada. Como no podía ser de otra manera, la base de este marco conceptual la constituía una serie de distinciones terminológico-conceptuales básicas, que Coseriu plasma en los esquemas que se reproducen en las figuras 1 y 2 (infra), gracias a los cuales podemos diferenciar, dentro de la lingüística, entre (i) la lingüística de las lenguas o del texto, como disciplinas históricas, (ii) la lingüística general y (iii) la teoría del lenguaje, esta última íntimamente relacionada, para Coseriu, con la filosofía:

\section{FIGURA 1}

Las tres clases de ciencias, según Coseriu (1969 [1975²]: 12)

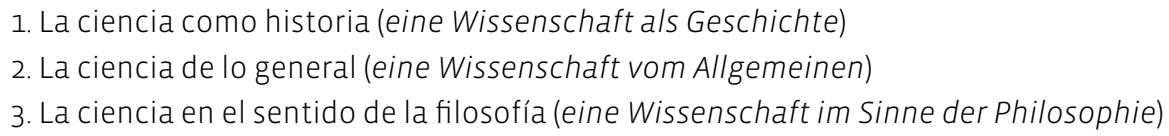

\section{FIGURA 2}

Las tres clases de preguntas científicas, según Coseriu (1969 [1975²]: 13)

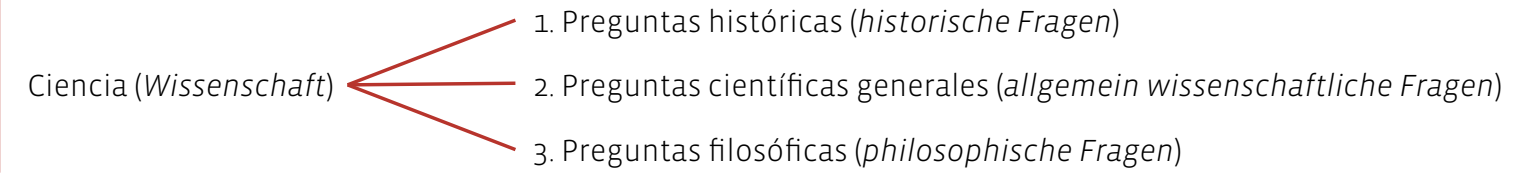

Aunque analizar con detenimiento estas diferenciaciones nos desviaría de los objetivos formulados en § 2, no puedo pasar por alto el hecho de que Coseriu contemple como tipo específico de conocimiento científico el histórico, que define como el tipo de ciencia que versa sobre objetos individuales considerados en su individualidad, y no en relación con su pertenencia a una determinada clase, ni tampoco el hecho de que precise que este tipo de ciencias históricas (entre las que se encuentran la lingüística de las lenguas y la lingüística del texto) no se interesa únicamente por el desarrollo de un individuo histórico (es decir, por el aspecto

11 "La situación de la investigación en el ámbito de la filosofía del lenguaje se revela, cuando se considera desde cerca, como [una situación] de confusión y abandono" (Coseriu, 1969 [1975²]: 1. Mi traducción; la cursiva es mía). 
diacrónico), sino también por la descripción de dicho individuo histórico en un determinado momento puntual (sincrónicamente). No quiero dejar de advertirlo porque me parece importante resaltar cómo esta noción de lo histórico, que en el capítulo primero de su Historia de la filosofía del lenguaje se propone, con una función propedéutica, desde la perspectiva de la filosofía de la lingüística, es perfectamente coherente - o, mejor dicho, absolutamente idéntica- a la noción de lo histórico que se maneja en Sincronía, diacronía e historia: "Una lengua, en el sentido corriente del término (lengua española, lengua francesa, etcétera), es por su naturaleza un «objeto histórico». [En nota:] Un objeto histórico «por su naturaleza» es un objeto individuado absolutamente, dentro de su especie, como tal y no otro [...]; es decir, un objeto que tiene nombre propio" (Coseriu, 19883: 20 y 20, n. 27; la cursiva es mía). Así las cosas, parece cobrar fuerza la convicción de que las distinciones que se establecen en el libro que Coseriu dedica a la teoría del cambio lingüístico son, claramente, de inspiración epistemológica (cf. infra §§ 3.3 y 4).

\subsection{La naturaleza filosófica de las distinciones coserianas}

La coincidencia que acabo de resaltar nos sirve para ver en qué medida los conceptos y las categorías con los que Coseriu aborda el problema del cambio lingüístico provienen, no de la lingüística, sino de la filosofía (en este caso de la filosofía de la lingüística, que es la encargada de distinguir tipos de conocimiento científico), algo que en Sincronía, diacronía e historia no se agota, ni mucho menos, en la definición de los objetos históricos, sino que se ve también con absoluta claridad en la distinción que Coseriu establece entre los

tres problemas diversos del cambio lingüístico, que a menudo se confunden: a) EL PROBLEMA RACIONAL del CAMBio (¿por qué cambian las lenguas?, es decir, ¿ipor qué no son inmutables?)²; b) el problema general de los Cambios, que, como se verá, no es un problema "causal”, sino "condicional” (¿en qué condiciones suelen ocurrir cambios en las lenguas?)"13; y c) EL PROBLEMA HISTÓRICO DE TAL CAMBIO DETERMINADO ${ }^{14}$ (Coseriu, 19883: 65-66; cursiva original; la versalita es mía).

En relación con estos tres tipos de problemas del cambio lingüístico, correlacionados -como se ve con mayor claridad en la figura 3- con tres tipos diversos de preguntas científicas y, por ende, con tres tipos de ciencias diferentes, más que la frontera entre la lingüística histórica y la general, o entre la lingüística histórica y la teoría del lenguaje, a Coseriu le preocupaba,

12 Adviértase que se trata de una pregunta filosófica, que compete a la teoría del lenguaje, que, como ya hemos visto, para Coseriu no puede ser autónoma con respecto a la filosofía.

13 Este es, por tanto, un problema de lingüística general.

Una cuestión que concierne, como es natural, a la lingüística histórica. 


\section{FIGURA 3}

Los tres problemas del cambio lingüístico en relación con los tres tipos de ciencias que establece Coseriu

\begin{tabular}{lll}
\hline a) Teoría del lenguaje (y filosofía) & $\begin{array}{l}\text { Problema racional del cam- } \\
\text { bio: problema teórico de la } \\
\text { mutabilidad de las lenguas }\end{array}$ & $\begin{array}{l}\text { ¿por qué cambian las lenguas? } \\
\text { ¿por qué no son inmutables? }\end{array}$ \\
\hline b) Lingüística general & $\begin{array}{l}\text { Problema general } \\
\text { de los cambios }\end{array}$ & $\begin{array}{l}\text { ¿en qué condiciones suelen } \\
\text { ocurrir cambios en las lenguas? }\end{array}$ \\
\hline \multirow{2}{*}{ Lingüística histórica } & $\begin{array}{l}\text { Problema histórico de tal } \\
\text { cambio determinado }\end{array}$ & $\begin{array}{l}\text { ¿por qué surgió el } \\
\text { futuro romance? }\end{array}$ \\
\hline
\end{tabular}

sobre todo, evitar la confusión entre la perspectiva racional — propia de la filosofía y de la teoría del lenguaje- y la perspectiva general, propia de la lingüística de idéntico nombre:

Efectivamente, el segundo problema es un problema de lo que se llama "lingüística general”; y, puesto que no hay propiamente una lingüística "general", salvo como generalización de los resultados de la lingüística histórica, ese problema es una generalización de ciertos aspectos de los problemas del tercer tipo [...]; asimismo, su solución es generalización de varias soluciones de problemas históricamente concretos y, a su vez, como acumulación de lo sabido acerca de los hechos históricos, ofrece hipótesis para la solución de nuevos problemas concretos. El primer problema, en cambio, es el problema teórico de la mutabilidad de las lenguas; y, en cuanto problema teórico, depende, ciertamente, del conocimiento de los "hechos", pues toda teoría es teoría de la experiencia (o sea, de lo real), pero su solución no es de ningún modo mera generalización de varias soluciones parciales (Coseriu, 19883: 66).

Pues bien, en relación con el tercero de los objetivos en este trabajo (cf., supra, § 2), lo interesante con respecto a la simbiosis que, en Coseriu, se da entre filosofía y lingüística es que la razón de ser de la distinción entre el problema racional de la mutabilidad del cambio lingüístico y el problema general de los cambios lingüísticos se debe, de nuevo, a una convicción epistemológica. En efecto, para él, el problema teórico de la mutabilidad de las lenguas es

(1) un problema previo, y de su solución depende el planteamiento correcto de los problemas del tipo b y c. Su propio planteamiento, como necesariamente ocurre en las ciencias del hombre, se funda en el "saber originario" acerca del lenguaje, es decir, en el conocimiento, anterior a toda ciencia, que el hombre tiene de sí mismo (Coseriu, 19883: 66; la cursiva es mía) ${ }^{15}$.

15 Dado que más adelante habremos de volver sobre esta cita, para facilitar su localización, y pese a que su longitud no lo requería, su texto se ha sangrado y, a diferencia del tratamiento que se había dado a otros pasajes literales reproducidos anteriormente, se identifica con el número 1. En lo sucesivo, se procederá de igual forma cuando se sepa que en un apartado posterior a una determinada cita se deba remitir nuevamente a ella. 
Y el error de confundir este problema teórico con un problema de lingüística general procede, para Coseriu, de la que en este sentido podemos arriesgarnos a considerar la confusión fundamental para él: la confusión entre ciencias del hombre y ciencias de la naturaleza:

(2) Uno de los errores que más afligen a la lingüística - y que también procede del considerar las lenguas como "cosas" y de la confusión entre ciencias del hombre y ciencias de la naturalezaes el de querer reducir los problemas teóricos (racionales) a problemas meramente "generales" (Coseriu, 19883: 66-67; la cursiva es mía) ${ }^{16}$.

Junto a la diferenciación entre el problema racional y el problema general del cambio lingüístico, otra de las distinciones coserianas que se basa en sus convicciones epistemológicas es la que, en la "Nota preliminar" a la edición española de las Lecciones de lingüística general (aparecidas originariamente en italiano en 1973), se establece entre teoría del lenguaje y lingüística general:

(3) en rigor, de acuerdo con mis convicciones epistemológicas, habría debido titular este libro Lecciones de teoría del lenguaje y lingüística general (Coseriu, 1981: 11; la cursiva es mía).

Si no lo hace - continúa - es "por razones prácticas y por concesión a la tradición, así como porque el libro se refiere también a otros problemas (en particular, a la teoría y a la interpretación histórica de la lingüística misma)" (Coseriu, 1981: 11; la cursiva es mía).

Que Coseriu concedía una gran importancia a la discusión de los fundamentos epistemológicos de las diversas corrientes y metodologías lingüísticas es algo que queda patente también en su oposición a muchos de los postulados de Chomsky7 o cuando, en su "Panorama de la lingüística iberoamericana (1840-1965)" se duele del escaso interés que a estas cuestiones había dedicado la lingüística hispanoamericana y brasileña:

Los lingüistas iberoamericanos se proponen, ciertamente, contribuir al progreso cualitativo (sic por cuantitativo) de la lingüística en Iberoamérica, elevándola al nivel de la lingüística europea o de la norteamericana, pero no se proponen, por lo común, contribuir al progreso cualitativo teórico y metodológico - de la lingüística como tal. A este último respecto, aspiran más bien a un progreso cuantitativo: a extender la lingüística científica ya existente a zonas inexploradas o poco exploradas. Así, pues, la lingüística iberoamericana es, en general, una lingüística que no aspira a la originalidad, que no tiene ambiciones teóricas y metodológicas [omito nota]. Su lema es aprender

16 A lo que añade: "En el caso del cambio lingüístico, ese error consiste en creer que el problema de la mutabilidad de las lenguas se resuelve encontrando la «causa», o todas las pretendidas "causas», de los muchos cambios particulares" (Coseriu, 19883: 66-67; cursiva original).

17 "Mi oposición a Chomsky y al chomskismo es, precisamente, de carácter epistemológico y está fundada en una epistemología muy seria” (Coseriu, 1968 [1977]: 358 y 358-360, n. 177; cursiva original). 
y aplicar, no crear o renovar. [...] Por la misma razón, también las discusiones teóricas y críticas son relativamente raras en Iberoamérica: se discuten hechos y opiniones, desde el punto de vista de teorías ya dadas, PERO No SE SUELEN DISCUTIR LAS TEORIAS MISMAS Y SUS FUNDAMENTOS EPISTEMOLÓGICOS (Coseriu, 1968 [1977]: 316-317; cursiva original; la versalita es mía).

\subsection{La filosofía de la lingüística de Eugenio Coseriu como fuente de sus dis- tinciones conceptuales}

Como ya se ha avanzado, una de las hipótesis principales de este trabajo, en relación con las interrelaciones entre lingüística y filosofía en la obra de Coseriu, es la de que, en el pensamiento de este autor, la reivindicación de la diferenciación como antídoto contra la confusión, el desorden y el caos que impiden el conocimiento es deudora, no de sus acercamientos a la filosofía del lenguaje, sino de sus incursiones en la filosofía de la lingüística. En esto estoy de acuerdo con lo que afirma Bota, en cuya opinión "la dimension déterminante du travail philosophique de Coseriu est d'ordre épistémologique, et sous-tend l'ensemble de sa

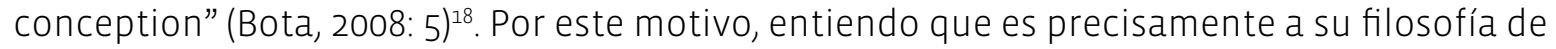
la lingüística a donde se debe acudir en busca del origen de algunas de las distinciones que nos van a interesar en lo que resta. Con todo, antes de introducirnos de lleno en la filosofía de la lingüística coseriana, resulta pertinente llamar la atención sobre cómo, en una de las citas que ya se han traído anteriormente a colación (concretamente la número 3) se puede comprobar cómo el compromiso con la distinción de que Coseriu hace gala en todo momento procede de sus convicciones epistemológicas:

en rigor, de acuerdo con mis convicciones epistemológicas, habría debido titular este libro Lecciones de teoría del lenguaje y lingüística general (Coseriu, 1981: 11; la cursiva es mía).

A la luz de estas palabras, a las que se recurrió páginas atrás para poner de relieve la diferenciación entre teoría del lenguaje y lingüística general, es evidente que Coseriu nos está advirtiendo de cuál es el papel que desempeñan sus convicciones epistemológicas en su incesante

18 El texto completo del fragmento del que se extrae esta cita es el siguiente: "Coseriu n'a pas fait de la philosophie un objet en soi, il ne l'a jamais professée en qualité de philosophe, mais en qualité de "scientifique du langage", lui accordant un statut opérationnel. Plus précisément, la philosophie a eu pour lui un rôle instrumental, à la fois dans la détermination du statut de l'objet de la science (le langage) et dans la détermination du statut de la démarche scientifique elle-même (la science du langage). Ce rôle est fondamental et permanent, dans la mesure où pour l'auteur il n'y a pas de science sans philosophie, même quand la science prétend s'en dégager complètement, même quand cette philosophie reste inconsciente ou n'est admise que partiellement. C'est pOurquOI LA DIMENSION DÉTERMINANTE DU TRAVAIL PHILOSOPHIQUE DE COSERIU EST D'ORDRE ÉPISTÉMOLOGIQUE, ET SOUS-TEND L’ENSEMBLE de SA CONCEPTION" (Bota, 2008: 5; Cursiva original; la versalita es mía). 
actividad delimitadora: tales convicciones epistemológicas son nada menos que el motivo principal por el que el título Lecciones de lingüística general no le complace y, por tanto, la razón de ser de la distinción entre la teoría del lenguaje (en alemán Sprachtheorie) - a la que concierne todo lo que en el lenguaje es universal y necesario (por ejemplo, los universales coserianos de la semanticidad, la alteridad, la historicidad, etc.) - y lingüística general (en alemán Sprachwissenschaft), a la que compete el estudio de lo general en las lenguas (cf. supra, fig. 3).

Ahora bien, ¿cuáles son exactamente estas convicciones epistemológicas? En uno de los pocos artículos que, en los últimos años, se han centrado en el pensamiento filosófico-científico coseriano, López Serena (2009), se sostenía que la postura fenomenológica de E. Coseriu podía encontrar acomodo dentro de la perspectiva hermenéutica en filosofía de la ciencia, un enfoque que en la lingüística contemporánea continúa vigente en la obra de autores como el finlandés Esa Itkonen. El rasgo distintivo de la epistemología hermenéutica es la necesidad de distinguir tajantemente las ciencias humanas de las ciencias naturales y esta es una distinción a la que, efectivamente, como ya hemos visto, Coseriu suele apelar ${ }^{19}$.

La diferenciación filosófico-científica entre ambos tipos de ciencias por parte de los autores que defienden la necesidad de tenerla en cuenta se basa en dos razones fundamentales: la distinta naturaleza del objeto de estudio y los diferentes tipos de conocimiento que caracterizan a unas ciencias y a otras. En este sentido, a mi modo de ver, la determinación de la naturaleza específica del lenguaje como objeto de estudio propio de las ciencias humanas es esencial para comprender el pensamiento filosófico-lingüístico de Coseriu. De hecho, tanto en la obra de este autor como en la de los filósofos de la ciencia hermenéuticos, la respuesta a la pregunta (i) qué tipo de objeto es el lenguaje decide también (ii) qué tipo de ciencia es la lingüística, (iii) así como qué tipo de explicación se considera legítima en una lingüística que se entienda como parte de las ciencias humanas.

En su calidad de conocimiento de segundo orden, y en tanto que filosofar aplicado al ámbito de la teorización lingüística (cf. Díez y Moulines, 1999), la filosofía de la lingüística es un saber que aborda, desde un nivel de abstracción superior al de la lingüística, el estudio tanto de la teoría del lenguaje como de la lingüística general - y, de nuevo, por este motivo, la razón de ser de esta distinción no puede ser más que epistemológica-. Así las cosas, pertenecen a su campo de acción las dos últimas cuestiones que se acaban de enumerar: la cuestión de (ii)

19 Recuérdese, a este respecto, el contenido de la cita que se enumeró como (2): "Uno de los errores que más afligen a la lingüística -y que también procede del considerar las lenguas como «cosas» y de la confusión entre ciencias del hombre y ciencias de la naturaleza- es el de querer reducir los problemas teóricos (racionales) a problemas meramente «generales»" (Coseriu, 19883: 66-67; la cursiva es mía). 
qué tipo de ciencia es la lingüística, así como la de (iii) qué tipo de explicación se considera legítima en esta disciplina, amén de cuestiones colindantes como la de qué tipo de relación se establece, en la lingüística, entre el sujeto y el objeto de la investigación y, en consecuencia, la de qué tipo de acto epistémico ponemos en práctica los lingüistas, en nuestros procesos de descubrimiento, dada nuestra condición simultánea de sujetos y objetos de la investigación.

Que el lingüista reúne esta doble condición sujeto-objeto de la investigación de la que no puede sustraerse era algo evidente para Coseriu. Lo hemos visto ya en el pasaje de Sincronía, diacronía e historia que se reprodujo en (1), donde se hacía hincapié en que la respuesta a las preguntas racionales o teóricas como la de la mutabilidad de las lenguas se había de fundar en el "saber originario" acerca del lenguaje. Y se puede comprobar también, en los dos extractos siguientes, que proceden, respectivamente, de "Forma y sustancia en los sonidos del lenguaje" y del "Panorama de la lingüística iberoamericana", que ya se trajo a colación anteriormente:

[E]l lingüista no puede eludir el hecho de que tiene experiencia del valor simbólico de los signos lingüísticos, por ser él mismo un individuo hablante: el científico no puede excluirse a sí mismo como hablante de su experiencia objetiva de los hechos lingüísticos (Coseriu, 1954 [1973]: 142; la cursiva es mía).

[E]I DLM [Departamento de Lingüística de Montevideo] se propuso elaborar una teoría lingüística Conforme a la realidad del lenguaje, tanto en su funcionamiento como en su desarrollo histórico, tarea que tomó a su cargo Coseriu, desarrollándola, en parte, simultáneamente con su actividad crítica [omito nota]. Los principios básicos de esa teoría son que la condición primera de toda teoría lingüística es el ser adecuada al objeto y que su fundamento es ineludiblemente el 'saber originario', es decir, el saber que el hombre tiene acerca de sí mismo en cuanto sujeto hablante (Coseriu, 1968 [1977]: 319-320).

En su defensa de un tipo de conocimiento propio para las ciencias del hombre, distinto al de las ciencias naturales, la corriente hermenéutica (cf. Bleicher, 1980; Itkonen, 1993), a la que entiendo, en línea con lo ya aducido en López Serena (2009), que se debe adscribir a Coseriu, se enfrenta al monismo metodológico característico de la epistemología positivista, que aboga por la unificación metodológica de las ciencias, de acuerdo con tres postulados fundamentales:

(i) el (mismo) método científico puede ser aplicado en todos los ámbitos de conocimiento sobre los que se desee obtener un saber máximamente justificado;

(ii) este método científico unitario se corresponde, idealmente, con el paradigma de las ciencias físicas;

(iii) de acuerdo con esto, los hechos de cualquier ámbito científico han de ser objeto de explicaciones causales deterministas o nomológico-deductivas (Hempel y Oppenheim, 1948), consistentes en la reducción de hechos individuales a manifestaciones de leyes generales. 
Por lo que respecta a Coseriu, que no emplea nunca la etiqueta monismo metodológico, en sus referencias a esta postura él habla, más bien, del "principio del naturalismo":

[E]N VIRTUD DEL PRINCIPIO DEL NATURALISMO, LAS LENGUAS SE CONSIDERAN, MÁS O MENOS EXPLICITAMENTE, COMO SI FUESEN OBJEtos u ORganismos naturales, dotados de "evolución" propia [omito nota]. Por consiguiente, se habla de "vida" de las lenguas y "vida" de las palabras, y, sin duda, a menudo se entiende que son metáforas, pero también las metáforas tienen su porqué y reflejan una determinada ideología ${ }^{[20]}$. Así también, se habla de "lenguas madres" " “lenguas hijas", de "familias" de lenguas, y, en parte, estas metáforas se difunden y enraízan en la terminología corriente, fuera de la lingüística.

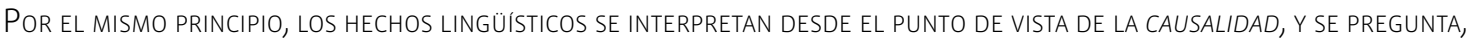
por ejemplo, cuál es la “causa" de tal o cual cambio linguistico. Así, puesto que la "evolución" constituye el problema básico, al observarse que, en la historia, se pasa de un estado de lengua A a un estado B, se plantea el problema de las "causas" que han determinado tal "evolución”. Es decir que no se considera como hecho primario la producción de las lenguas, o sea, la creatividad lingüística como tal y su objetivación histórica (el Ilamado "cambio"), sino, en cada caso, el estado de lengua, que - como los objetos naturales - sin causas, no debería cambiar. En cuanto a las causas mismas, se estima que podrían ser análogas a las comprobadas en el mundo natural; y se ha hablado hasta del influjo del clima y del ambiente geográfico sobre las lenguas, así como, en la historia literaria, Hipólito Taine pretendía explicar el desarrollo de la literatura por determinaciones e influjos varios, incluidos los del ambiente geográfico (pero, afortunadamente, también los del ambiente social) (Coseriu, 1981: 48-49; la cursiva resaltada en versalitas y la versalita son mías)²1.

El principio del naturalismo significa, en primer lugar y en sentido general que todos los hechos se reducen al tipo de los hechos naturales [...]. En consecuencia, se estima que todos los hechos - también los que pertenecen a la esfera propiamente humana, como el arte o el lenguaje- están sujetos a los principios de causalidad y de necesidad que valen en el mundo de la naturaleza. Es decir que también los hechos culturales se consideran como si fuesen hechos naturales y como debidos a "causas" y gobernados por leyes de necesidad. El corolario metodológico de esto es que la ciencia natural se toma como modelo ideal de toda ciencia y que también a los hechos culturales se aplican planteamientos y métodos "naturalistas". Por ello, lo que se busca son las causas de los hechos y las leyes de su "evolución", una legalidad suya de tipo natural, exigencia, ésta, satisfecha cuando se logre descubrir las leyes que determinan y regulan los hechos y, en particular, las leyes de su desarrollo. Además, de acuerdo con el principio formulado por Augusto Comte, "savoir pour prévoir afin de pourvoir", se estima que el conocimiento de los hechos y la generalización nos permitirían establecer leyes de carácter general que, a su vez, consentirían prever desarrollos futuros. Por lo tanto, se considera que una ciencia cualquiera es propiamente tal y ha alcanzado su madurez en el momento en que es capaz de prever (Coseriu, 1981: 40; la cursiva es mía).

20 Sobre el peligro de las metáforas naturalistas en la lingüística histórica diacrónica, cf. López Serena (2014a).

21 Sobre el problema de la causalidad en la lingüística histórica diacrónica, cf. Hammarström (201314) y Winter-Froemel (2013-14). 


\section{Los principios epistemológicos que vertebran Sincronía, diacronía e historia}

\subsection{El problema de las aproximaciones naturalistas y causalistas al cambio lingüístico}

Sin perder de vista el tercero y más importante de los objetivos de este trabajo, el de analizar qué aspectos del pensamiento lingüístico de Coseriu tienen su origen en cuestiones de naturaleza filosófica, creo que es importante señalar cómo los dos asertos anteriores, que proceden de Lecciones de lingüística general, coinciden exactamente con las críticas que Coseriu hace al naturalismo en Sincronía, diacronía e historia, una obra de la que, desafortunadamente, López Serena (2009) no se hace eco, pese a que probablemente constituya el tratado epistemológico más completo elaborado por E. Coseriu. Así, en relación con la confusión entre la pregunta racional y la pregunta general acerca del cambio lingüístico que ya se ha abordado anteriormente, Coseriu señala que la razón de que ambas se planteen en términos en apariencia idénticos "se debe [...], en parte, a deficiencias terminológicas generales de las ciencias del hombre, que tan a menudo adoptan el vocabulario y las expresiones propias de las ciencias de la naturaleza. Y, sobre todo, se debe a la identificación o confusión entre los dos problemas, que, a su vez, radica en la misma actitud naturalista con respecto a la lengua" (Coseriu, 19883: 111; la cursiva es mía). Esta misma actitud naturalista se detecta, según Coseriu, en el "sociologismo durkheimiano" de Saussure, doctrina impregnada, en su opinión, "de la concepción schleicheriana de las lenguas como «organismos naturales»"; de ahí que, a su modo de ver, "la concepción sociologista de Saussure apare[zca] en muchos casos como una traducción en términos sociológicos de la misma concepción naturalista de Schleicher" (Coseriu, 19883: 42). Y la misma concepción naturalista estaba también en la base de los dos vicios fundamentales que Coseriu denuncia en su revisión de cómo había abordado el estructuralismo el problema del cambio lingüístico:

[E]l modo como el estructuralismo ha planteado el problema implica dos vicios fundamentales que revelan todo el peso de su tradición naturalista. En primer lugar, la confusión entre el problema empírico general de los cambios y el problema racional de la mutabilidad de las lenguas: la creencia de que las varias explicaciones parciales podrían contribuir a resolver el problema de "por qué cambian las lenguas", lo cual es imposible, pues, como se ha visto, se trata de un problema de otro orden y de otra índole. En segundo lugar, el error de creer que se sigue planteando el problema positivista de las "causas", mientras que, en realidad, se plantea el problema de las condiciones y modalidades generales de los cambios, es decir, un problema de historia generalizada y formalizada (Coseriu, 19883: 211; la cursiva es mía).

En qué medida el error de abordar el problema del cambio lingüístico en términos causales, un error que trasciende las fronteras del estructuralismo, es herencia del denostado principio del naturalismo se ve aún más claro en el pasaje siguiente: 
[L]as explicaciones culturales y funcionales de los cambios no son de ningún modo "causales". La idea misma de 'causalidad' en la llamada "evolución” idiomática es un residuo de la vieja concepción de las lenguas como "organismos naturales”, así como del sueño positivista de descubrir las supuestas "leyes" del lenguaje (o de las lenguas) y de transformar la lingüística en una "ciencia de leyes” análoga a las ciencias físicas (Coseriu, 19883: 178).

Como ya se ha apuntado, frente al monismo metodológico, o principio del naturalismo, propio de la filosofía de la ciencia positivista, se opone, en el antipositivismo coseriano, el principio de la cultura 0 ,

(4) más exactamente, la distinción entre objetos naturales y objetos culturales y, por consiguiente, entre ciencias de la naturaleza y ciencias de la cultura. Es decir que YA NO SE ACEPTAN LAS ciencias naturales como modelo de la ciencia en General, sino que se entiende que las ciencias, precisamente para ser tales, deben ser diferentes, SEGÚn LA ÍNDOLE DE SU OBJETo (Coseriu, 1981: 67-68; énfasis original en cursiva; versalitas mías).

\subsection{La distinción entre ciencias naturales y ciencias del hombre en el pensa- miento de Coseriu}

De acuerdo con lo anterior, para los defensores de la hermenéutica, debido a la diferente naturaleza del objeto de estudio de ciencias naturales y ciencias humanas y a la diferente relación que el sujeto de la investigación establece con tales objetos, el tipo de explicación que se emplea en uno y otro ámbito ha de ser también, necesariamente, disímil (cf. infra fig. 4). Por un lado, en relación con la naturaleza manifiestamente desigual de sus respectivos objetos de estudio, cabe señalar que mientras que los fenómenos humanos poseen un carácter eminentemente normativo (social) — cuyas reglas es perfectamente posible violar-, las leyes naturales son de carácter necesario; de ahí que en ellas los contraejemplos no se conciban como violaciones de las reglas, sino como refutación de las leyes. La oposición está, por tanto, basada en (i) el carácter universal de los fenómenos naturales — sujetos a leyes de causalidad y necesidad y susceptibles, por tanto, de predicción-, en contraposición con la condición histórica de lo humano, donde priman la libertad o libre albedrío de acatar o violar las reglas y las explicaciones finalistas, y no causalistas. Por otro lado, por lo que respecta a la distinta relación entre sujeto y objeto de la investigación en uno y otro tipo de ciencias, ambos son independientes en las naturales y coincidentes en las humanas, en las que el hombre es a un tiempo sujeto y objeto de la investigación. En consecuencia, el procedimiento (acto epistémico) que se requiere para alcanzar el conocimiento en las ciencias naturales, que suele ser el de observación, no resulta necesariamente pertinente en el caso de las ciencias naturales, que se valen, en numerosas ocasiones, de la intuición (cf. Itkonen, 2003 [2008]; López Serena, 2009, 2014b). Expuestas en forma de esquema, las tres oposiciones que se acaban de mencionar darían lugar a la figura 4 (cf. infra). 


\title{
FIGURA 4
}

La oposición entre ciencias naturales y ciencias humanas

\begin{tabular}{|c|c|c|}
\hline & CIENCIAS NATURALES & CIENCIAS HUMANAS \\
\hline NATURALEZA DEL OBJETO DE ESTUDIO & $\begin{array}{l}\text { objetos naturales, de } \\
\text { carácter universal }\end{array}$ & $\begin{array}{l}\text { objetos humanos de naturaleza } \\
\text { histórico-normativa (social), } \\
\text { dotados de libre albedrío }\end{array}$ \\
\hline $\begin{array}{l}\text { TIPOS DE LEYES/REGLAS } \\
\text { A QUE SE SUJETAN }\end{array}$ & $\begin{array}{l}\text { leyes universales de } \\
\text { causalidad-necesidad, que } \\
\text { permiten la predicción }\end{array}$ & $\begin{array}{c}\text { normas o reglas históricas } \\
\text { que es posible violar }\end{array}$ \\
\hline RELACIÓN SUJETO-OBJETO INVESTIGACIÓN & independientes & coincidentes \\
\hline $\begin{array}{l}\text { TIPOS DE EXPLICACIONES } \\
\text { CARACTERISTICAS }\end{array}$ & causalistas & finalistas \\
\hline ACTO EPISTÉMICO PROTOTIPICO & observación & intuición \\
\hline
\end{tabular}

No es este el lugar para abordar con detalle todas estas cuestiones, pero sí creo necesario subrayar, dado mi propósito de resaltar la íntima relación, que en el pensamiento coseriano, existe entre filosofía y lingüística, cómo absolutamente toda la exposición y la argumentación con las que Coseriu construye su teoría del cambio lingüístico se estructuran, precisamente, de acuerdo con las tres distinciones fundamentales que se acaban de enumerar. Así, por ejemplo, con respecto a la necesidad de deslindar tajantemente las ciencias humanas de las naturales, a lo ya aducido por Coseriu en la cita número (4), supra, cabe añadir lo siguiente:

\begin{abstract}
A todAS LAS ACTITUDES CAUSALISTAS Y A LAS CONFUSIONES QUE ELLAS IMPLICAN, HAY QUE OPONER LA DISTINCIÓN —CLARAMENTE establecida desde Kant— entre el “mundo de la necesidad” y el "mundo de la libertad”. Asimismo, a los intentos declarados o no declarados del positivismo viejo y nuevo de reducir toda ciencia a ciencia física, HAY QUE OPONER LA FUNDAMENTAL DIVERSIDAD ENTRE LOS HECHOS NATURALES Y LOS CULTURALES $y$, por lo tanto, entre las ciencias físicas y las humanas. Esto no implica ningún desdén por las ciencias físicas que, naturalmente, son las únicas adecuadas a su objeto. Pero implica entender que sus postulados y métodos (salvo por lo que atañe a la descripción material) no son aplicables a los objetos culturales, puesto que en éstos lo exacto, lo positivo, lo que efectivamente se da y se comprueba, son la libertad y la intencionalidad, la invención, la creación y la adopción libres, motivadas sólo finalísticamente. EN LOS FENÓMENOS DE LA NATURALEZA CORRESPONDE, SIN DUDA, BUSCAR UNA NECESIDAD EXTERIOR, O CAUSALIDAD; EN LOS FENÓMENOS CULTURALES, EN CAMBIO, LO QUE CORRESPONDE BUSCAR ES UNA NECESIDAD INTERIOR, O FINALIDAD (Coseriu, 19883: 193-194; cursiva original; la versalita es mía).
\end{abstract}

Por lo que respecta al rechazo frente a las explicaciones causales y a la posibilidad de predicción en las ciencias humanas, interesan también las siguientes líneas:

En el fondo, la perplejidad frente al cambio lingüístico y la tendencia a considerarlo como fenómeno espurio, provocado por "factores externos", se deben al hecho de partir de la lengua abstracta -y, por lo tanto, estática一, separada del hablar y considerada como cosa hecha, como ergon, sin 
siquiera preguntarse qué son y cómo existen realmente las lenguas y qué significa propiamente un "cambio" en una lengua. De aquí también el planteamiento del problema del cambio en términos causales, puesto que los cambios en las "cosas" desligadas de la intencionalidad de todo sujeto se atribuyen, precisamente, a "causas". Pero la lengua no pertenece al orden causal sino al orden final (Coseriu, 19883: 29; cursiva original).

Como trasluce en las formulaciones anteriores, la distinción entre ciencias humanas y ciencias naturales en Coseriu no es importante solamente como distinción epistemológica, aislada de su lingüística, sino que resulta fundamental precisamente porque determina la manera en que se abordan cuestiones de teoría del lenguaje y de lingüística general. Pero además, aparte de esta distinción, concomitante a la que se establece entre causalidad frente a finalidad, para Coseriu, como ya se ha tenido la ocasión de comprobar en algunos otros pasajes de los que se han reproducido anteriormente, la especificidad de las ciencias humanas reside también en la estrecha vinculación que en ellas se produce entre el sujeto y el objeto de la investigación. Finalmente, por lo que concierne al acto epistémico propio de las ciencias humanas, en relación con el cual Coseriu habla a veces ${ }^{22}$ de saber originario, otras de reducción eidética y otras de intuición o captación de lo evidente, creo que pueden ser de interés los siguientes pasajes, procedentes, insisto en ello, de nuevo, de una obra lingüística, Sincronía, diacronía e historia:

[E]n la lingüística, como en todas las ciencias humanas, el fundamento debe ser, y es, el "saber originario" que el hombre tiene acerca de sí mismo (Coseriu, 19883: 182; la cursiva es mía).

[E]n las ciencias del hombre, aquello que se presenta a la conciencia con carácter de evidencia, lejos de poder desecharse como "sans portée", debe tomarse como base de la investigación (Coseriu, 19883: 41; la cursiva es mía).

[C]on respecto a los objetos culturales, el conocimiento eidético es necesariamente primario (anterior al estudio empírico), puesto que es constitutivo de los objetos como tales (Coseriu, 19883: 191; la cursiva es mía).

[E]n las ciencias del hombre no caben hipótesis con respecto a lo universal. El lugar que en las ciencias físicas corresponde a las hipótesis lo ocupa en las ciencias humanas el saber natural que el hombre posee acerca de sus actividades y de los objetos que él mismo crea (Coseriu, 19883: 191; la cursiva es mía).

[L]a finalidad, en cuanto "causalidad subjetiva", no puede conocerse (reconocerse) más que subjetivamente, mediante una EXPERIENCIA INTERIOR, ya que no se trata de un hecho exteriormente comprobable. Por lo tanto, el problema que debe plantearse en cada caso particular no es: “¿por qué [por cuáles circunstancias empíricamente objetivas] ocurrió tal cambio?”, sino: “ipara qué [con qué finalidad] yo, disponiendo de tal sistema determinado y hallándome en tales y cuales circunstan- 
cias históricas, cambiaría A en B, abandonaría el elemento C o crearía el elemento D?"[23] [En nota: [...] Ello no ocurre sólo con los cambios, sino con todos los hechos lingüísticos, que no pueden entenderse como tales más que mediante una reinterpretación interior [....] Más aún: no sólo así debe hacerse, sino que cabe decir que, en realidad, y por debajo de la eventual terminología causalista, así se hace y así se ha hecho en cada caso en que el problema de un cambio particular se ha planteado con sentido y, en lo esencial, correctamente (Coseriu, 19883: 205-206 y 206, n. 45; cursiva original; la versalita es mía).

Creo que a la luz de este ramillete de citas escogidas no es posible albergar la más mínima duda sobre el hecho, para mí, desde luego, evidente, de que Sincronía, diacronía e historia, un libro de teorización lingüística, y más concretamente, de teorización acerca del cambio lingüístico, no se puede entender íntegramente a menos que se sea consciente de que, en su arranque, la confusión esencial que Coseriu se propone atajar es una confusión cuya resolución atañe a la filosofía de la lingüística, que es, precisamente, la disciplina responsable de evaluar la idoneidad o falta de idoneidad de la aplicación de planteamientos causalistas a determinados objetos de investigación. De hecho, como hemos visto, Coseriu acude a reflexiones epistemológicas una y otra vez en esta su obra cumbre sobre el cambio lingüístico, bien para insistir en el error de enfoque y de método que encierra el planteamiento causalista, bien para abogar por la diferenciación entre ciencias naturales y ciencias humanas y por la consecuente aplicación, en estas últimas, de una óptica finalista, bien para describir el acto epistémico del recurso al saber originario o la intuición de que el lingüista dispone como hablante de la lengua que estudia.

\subsection{Las fuentes de la epistemología coseriana}

Aunque ello constituiría, realmente, el objetivo de otro trabajo distinto a este, en relación con las interconexiones que, en la producción científica de Coseriu, se detectan por doquier entre su filosofía de la lingüística y su filosofía del lenguaje, conviene señalar que no menos interesante que la lectura epistemológica de Sincronía, diacronía e historia que se ha propuesto aquí es reparar en cómo las distinciones filosófico-científicas detectadas en esta obra, y que parecen claves en el pensamiento coseriano, se pueden rastrear con facilidad en varios de los filósofos de los que se ocupa en su Historia de la filosofía del lenguaje. Por poner, al menos, unos pocos ejemplos ilustrativos en este sentido, la diferenciación entre necesidad o causalidad y libertad, que hemos visto atribuida a Kant, se vincula también, naturalmente, con la figura de Aristóteles: "Entendemos distinguir netamente el ámbito de la libertad del ámbito

23 Para una aplicación de este tipo de análisis finalista al examen epistemológico de los procedimientos explicativos característicos de la teoría de la gramaticalización, cf. López Serena (2014a). 
de la necesidad. En sus términos actuales, esta distinción es kantiana; pero ya Aristóteles subraya varias veces que la motivación finalista es de un tipo especial” (Coseriu, 1988²: 201).

Con respecto a esta misma diferenciación, fundamento de la distinción concomitante entre ciencias naturales y ciencias del hombre o de la cultura, Coseriu apunta también a la figura de Giambattista Vico (1668-1774), a quien dedica uno de los capítulos del segundo volumen de la edición más reciente de Geschichte der Sprachphilosophie, la de 2015, y a quien en otro lugar identifica como "el gran precursor y casi fundador de las ciencias de la cultura en su sentido propio", en virtud de una distinción olvidada e ignorada por el positivismo, "Ilegando así a identificar los objetos culturales con los naturales y a reducir todas las ciencias (salvo las matemáticas) al tipo de las ciencias de la naturaleza. Sólo a fines del siglo XIX y en los primeros años de nuestro siglo se vuelve a insistir en la misma distinción, sobre todo en Alemania, aunque sin relación directa con Vico y más bien con referencia a Kant y a su distinción entre 'necesidad' y 'libertad'” (Coseriu, 1981: 69-70).

Para Coseriu es también relativamente importante el pensamiento de Edmund Husserl (1859-1938). Del maestro de Heidegger (1889-1976), a quien, sin embargo, apenas se menciona en la Historia de la filosofía del lenguaje, parece ser la inspiración de Coseriu en aspectos como el ansia por la captación intuitiva de las esencias (Wesensanschauung), o por explicar las cosas, los fenómenos, tal como se aparecen a nuestra conciencia, como son desde dentro, así como la invocación al procedimiento de reducción eidética o a la experiencia antepredicativa como origen del conocimiento. De hecho, el principio general que orienta el proceder fenomenológico radica en la convicción de que "toda intuición en que se da algo originariamente es un fundamento de derecho del conocimiento" (Husserl, Ideas I, ápud Ruiz, 2006: 70)24. Tal conocimiento originario, o experiencia antepredicativa, a la que se accede mediante la intuición, y que tiene como objeto la captación de las esencias, de lo dado a la conciencia, pero en su mismidad, precisa, por tanto, de un procedimiento de reducción eidética. Este tiene como propósito la descripción de lo individual, pero no qua individual, sino en busca de su forma esencial o eidos, de lo que esencialmente y a priori le pertenece; de ahí el imperativo coseriano de adecuarse, en sus planteamientos, a la naturaleza o "íntima realidad" del lenguaje, y su empeño por "contribuir a una mayor comprensión de la íntima realidad y de la modalidad de ser de esa compleja actividad humana que es el lenguaje", así como por "hacernos comprender mejor la naturaleza de los sistemas histórico-culturales a los que llamamos comúnmente lenguas y el factor intrínseco de su desarrollo: el cambio lingüístico, el mecanismo de su producción y difusión” (Coseriu, 19883: 14).

Y, por supuesto, aparte de Husserl o de Vico, es también esencial, en la filosofía de la lingüística de Coseriu, la postura de Humboldt, el único filósofo del lenguaje que, para el maes- 
tro rumano, estaba al nivel de Aristóteles y Hegel (Coseriu, 1969 [1975²]: 8). En relación con él, Coseriu asevera, por ejemplo, que este, consciente de que "el método lingüístico no puede ser el de los naturalistas, dado que se trata de un 'objeto de naturaleza totalmente distinta'” (Coseriu, 1954 [1977]: 241; la cursiva es mía), rechaza decididamente la posibilidad de establecer "[u]na clasificación como la usual en las ciencias naturales [...], con lo cual señala también el naturalismo de tales intentos y ello en una época en la que la distinción entre ciencias de la naturaleza y ciencias de la cultura distaba mucho de ser obvia:

Por dos razones, que ponen en entredicho toda la cuestión, ha de rechazarse de una vez por todas y para siempre la clasificación, tan frecuentemente propugnada, de las lenguas según el modelo de la clasificación de los objetos naturales. Las ciencias naturales no se ocupan de lo espiritual ni de lo individual, y una lengua es una individualidad espiritual. En lo inorgánico no hay una individualidad que pudiera considerarse como un ser autónomo, y en lo orgánico las ciencias naturales no descienden hasta el individuo (Humboldt, Über die Verschiedenheiten des menschlichen Sprachbaues, manuscrito de los años 1827-1829, ed. en Werke in fünf Bänden. A. Flitner y K. Giel, tomo 2, Schriften zur Sprachphilosophie. Stuttgart, 1963. pág. 190, ápud Coseriu, 1972 [1977]: 161; la cursiva no preceptiva es mía).

Significativamente, Coseriu establece un paralelismo entre la postura -que hoy llamaríamos hermenéutica - de Humboldt y la suya propia, frente a la postura naturalista de Schleicher, que Coseriu considera el Chomsky del siglo XIX: "La confusión corriente respecto a la tipología lingüística de Humboldt se debe, muy probablemente, sobre todo a la gran influencia de Schleicher, que, en tantos aspectos, llegó a determinar los caminos de la lingüística posterior" (Coseriu, 1972 [1977]: 183). Y añade en nota a pie de página:

Hoy, apenas si se puede tener una idea exacta del alcance de esta influencia. Schleicher fue el Chomsky de su época y tuvo también sus Katz y Fodor, sus Postal y Lees, que entonces se llamaban Max Müller, Hovelacque y Pezzi. La lingüística ha necesitado todo un siglo para liberarse de varias tesis arbitrarias de Schleicher, y todavía hoy no se ha liberado totalmente de todas ellas. Esperemos que no necesite tanto para liberarse del nuevo y mucho más peligroso schleicherismo (Coseriu, 1972 [1977]: 183, n. 24; la cursiva es mía).

\section{Recapitulación y cuestiones pendientes}

Una de las constantes más representativas de todas las obras coserianas es su articulación en torno a un conjunto de distinciones terminológicas y conceptuales, imprescindibles en el pensamiento de este autor. Otra de las constantes en su actividad científica parece ser la indisolubilidad de la lingüística y de la filosofía, tan íntimamente conectadas en su pensamiento que muy difícilmente encontraremos, en su producción, cuestiones analizadas únicamente desde la perspectiva de la lingüística. Más bien al contrario, lo habitual es que, a las consideraciones lingüísticas se sumen, en ocasiones, consideraciones propias de la filosofía del lenguaje o de 
la filosofía de la lingüística. De hecho, como he tratado de poner de relieve en varias ocasiones a lo largo de estas páginas, parece que la fijación de Coseriu por partir siempre, independientemente del problema lingüístico concreto del que deseara ocuparse, de un determinado conjunto de distinciones y su querencia por el establecimiento de estas distinciones se explican, justamente, por la naturaleza hondamente epistemológica de todas sus aportaciones.

El trasfondo epistemológico del pensamiento coseriano -y, por tanto, la filosofía de la lingüística de este autor - sale a la luz, a veces, en formulaciones explícitas, en algunas de las obras de las que proceden la mayoría de las citas literales que se han utilizado en este trabajo, como ilustración de las ideas que se han ido desgranando a lo largo de sus páginas (Sincronía, diacronía e historia es un ejemplo paradigmático en este sentido). Pero más habitual que esto es que, en las contribuciones de Coseriu a la teorización lingüística, sus convicciones epistemológicas subyazcan a todo el conjunto de su argumentación, pero sin llegar necesariamente a hacerse manifiestas.

La gran mayoría de tales convicciones epistemológicas, así como de los conceptos y categorías filosófico-científicos que Coseriu hace suyos, proceden del corpus de pensamientos de algunas de las principales figuras de las que se ocupa en su Historia de la filosofía del lenguaje: Aristóteles, Vico, Husserl, Humboldt. Esto redunda en la percepción de que hay, pues, en Coseriu, una vinculación innegable entre filosofía de la lingüística, filosofía del lenguaje y lingüística, de tal manera que sus formas de proceder idiosincrásicas parecen determinadas por la coherencia epistemológica de todo su pensamiento, pero su epistemología hermenéutico-fenomenológica depende, a su vez, de decisiones sobre la ontología del lenguaje que proceden de la filosofía del lenguaje y que traspasan la frontera de lo filosófico para impregnar también su teoría del lenguaje y sus lingüísticas general, del hablar, de las lenguas y del texto. A este respecto, a los objetivos concretos enunciados al principio de este artículo (cf. supra $\S 2$ ), se ha de sumar también el propósito de llamar la atención sobre todo este entramado de relaciones presentes en la lingüística y en la filosofía de Coseriu, así como el de poner de relieve cómo, en el maestro rumano, la una es inconcebible sin la otra. Quedan para el futuro la descripción pormenorizada de las múltiples láminas y aristas de dicho entramado, el análisis epistemológico de otras obras lingüísticas de este autor, el examen, en profundidad, de las fuentes filosóficas de las que bebe Coseriu, así como de la síntesis que de ellas ofrece la Geschichte der Sprachphilosophie. Estas tareas difícilmente podrán ser obra de una única persona; de ahí la necesidad de subrayar, al menos, su importancia.

\section{Referencias bibliográficas}

AlBRECHT, Jörn, 2015: “La sémantique d’Eugenio Coseriu et ses sources épistemologiques dans la philosophie du langage" en Christoph GéRARD y Régis Missire (eds.): Eugenio Coseriu aujour d’hui. Linguistique et philosophie du langage, Limoges: Lambert-Lucas, 35-50. 
BARber, Alex (ed.), 2003: Epistemology of Language, Oxford: Oxford University Press.

Bernardo Paniagua, José María, 1995: La construcción de la lingüística. Un debate epistemológjco, Valencia: Universidad (LynX, Annexa 9).

Bernardo Paniagua, José María, 1999: “Epistemología e historia de la lingüística” en Ángel López Garcí (ed.): Lingüística general y aplicada, Valencia: Universidad, 377-403.

Bleicher, Josef, 1980: Contemporary hermenutics. Hermeneutics as method, philosophy and critique, Londres, etc.: Routledge \& Kegan Paul.

BотA, Cristian, 2008: "Eugenio Coseriu: linguistique et philosophie du langage. Un modèle complexe du fonctionnement langagière", Texto! XIII (1), 1-15 [http://www.revue-texto.net/docannexe/file/102/bota_coseriu.pdf, fecha de consulta: 8 de diciembre de 2017].

Bunge, Mario, 1980: Epistemología, Barcelona: Ariel.

Bunge, Mario, 1983: Lingüística y Filosofía, Barcelona: Ariel.

CARR, Philip, 1990: Linguistic Realities. An autonomist metatheory for the generative enterprise, Cambridge: Cambridge University Press.

CARR, Philip, 1994: "Philosophy of Linguistics and of Science" en R. E. Asher (ed.): The Encyclopedia of Language and Linguistics, Oxford: Pergamon Press, vol. 6, 3027-3028.

Carr, Philip, 20062: "Philosophy of Linguistics" en Keith Brown (ed.): Encyclopedia of Language and Linguistics, Ámsterdam: Elsevier, 331-337.

CARR, Philip, 2006: "The ontology and epistemology of linguistic objects" en Sylvain Auroux (ed.): History of the language sciences/Geschichte der Sprachwissenschaften/Histoire des sciences du langage. An International Handbook on the Evolution of the Study of Language from the Beginnings to the Present, Berlín / Nueva York: Walter de Gruyter, vol. 3, 2571-2579.

Chalmers, Alan F., 1982: ¿Qué es esa cosa llamada ciencia? Una valoración de la naturaleza y el estatuto de la ciencia y sus métodos, Madrid: Siglo XXI. (Trad. del original inglés de 1976).

Coseriu, Eugenio, 1952 [1973]: “Sistema, norma y habla” en Teoría del lenguaje y lingüística general. Cinco estudios, Madrid: Gredos, 11-113. Publicado originariamente en Revista de la Facultad de Humanidaes y Ciencias (Montevideo), 9, 113-177, y en edición independiente, Montevideo, 1952.

Coseriu, Eugenio, 1953 [1977] / 1996: “Amado Alonso (1896-1952)” en Tradición y novedad en la ciencia del lenguaje, Madrid: Gredos, 251-263. Publicado originariamente en Revista de la Facultad de Humanidades y Ciencias (Montevideo), 10, 31-39, y, en edición independiente, Montevideo, 1953. Reimpreso con una nota en Luis Jaime Cisneros y José Luis Rivarola (eds.): Centenario de Amado Alonso (1896-1996). Temas de Filología hispánica, Lexis, XX, 1-2, 1996, 31-41. 
Coseriu, Eugenio, 1954 [1973]: "Forma y sustancia en los sonidos del lenguaje" en Teoría del lenguaje y lingüística general. Cinco estudios, Madrid: Gredos, 115-234. Publicado originariamente en: Revista de la Facultad de Humanidades y Ciencias (Montevideo), 12, 1954, 143-217, y en edición independiente, Montevideo.

Coseriu, Eugenio, 1954 [1977]: "Raíces humboldtianas de la lingüística moderna” en Tradición y novedad en la ciencia del lenguaje, Madrid: Gredos, 138-141. Publicado originariamente en la Revista Azul 2 (Montevideo), 1954.

Coseriu, Eugenio, 1955-56 [1973]: "Determinación y entorno. Dos problemas de una lingüística del hablar" en Teoría del lenguaje y lingüística general. Cinco estudios, Madrid: Gredos, 282323. Publicado originariamente en Romanisches Jahrbuch VII, 1955-56, 29-54.

Coseriu, Eugenio, 1956-57: El problema de la corrección idiomática, Montevideo, manuscrito inédito custodiado en el Archivo Coseriu de la Universidad de Tubinga (Nr. B XXXIV, 16) (www.coseriu.de). Cf. ahora también Eugenio Coseriu, 2019: Competencia lingüística y criterios de corrección (ed. de Alfredo Matus y José Luis Samaniego, texto revisado y autorizado por Eugenio Coseriu), Sevilla: Editorial Universidad de Sevilla.

Coseriu, Eugenio, 1957 [1973]: “Logicismo y antilogicismo en la gramática” en Teoría del lenguaje y lingüística general. Cinco estudios, Madrid: Gredos, 235-260. Publicado originariamente en Revista Nacional (Montevideo), 189, 1957, 456-473, y en edición independiente en Montevideo, 1957, 1958.

Coseriu, Eugenio, 1968 [1977]: "Panorama de la lingüística iberoamericana (1940-1965)" en Tradición y novedad en la ciencia del lenguaje, Madrid: Gredos, 264-364. Publicado originariamente en inglés en Thomas A. Seabeok (ed.): Current Trends in Linguistics, IV, Ibero-American and Caribbean Linguistics, La Haya: Mouton, 1968, 5-62.

Coseriu, Eugenio, 1969 [1975²]: Die Geschichte der Sprachphilosophie von der Antike bis zur Gegenwart. Eine Übersicht. Teil II: Von Leibniz bis Rousseau. (Autorisierte Nachschrift von Gunter Narr), Tubinga: Gunter Narr.

Coseriu, Eugenio, 1972: Die Geschichte der Sprachphilosophie von der Antike bis zur Gegenwart. Eine Übersicht. Teil I: Von der Antike bis Leibniz. (Autorisierte Nachschrift von Gunter Narr und Rudolf Windisch), Tubinga: Gunter Narr.

Coseriu, Eugenio, 1972 [1977]: "Sobre la tipología lingüística de Wilhelm von Humboldt. Contribución a la crítica de lo tradicional en la historia de la lingüística”, en Tradición y novedad en la ciencia del lenguaje, Madrid: Gredos, 142-184. Publicado originalmente en Wolfgang Eıtel y Johannes Höste (eds.): Beiträge zur vergleichenden Literaturgeschichte. Festschrift Kurt Wais zum 65. Geburtstag, Tubinga: De Gruyter, 1972, 107-135.

Coseriu, Eugenio, 1980: “Interdisciplinarità e linguaggio” en Giorgio Braga (ed.): L'accostamento interdisciplinare allo studio del linguaggio, Milán: Franco Angeli, 43-65. 
Coseriu, Eugenio, 1981: Lecciones de lingüística general, Madrid: Gredos.

Coseriu, Eugenio, 1988: "Die Ebenen des sprachlichen Wissens. Der Ort des ,Korrekten“ in der Bewertungsskala des Gesprochenen” en Jörn AlBRECHT, Jens LüdTKE y Harald Thun (eds.): Energeia und Ergon. Studia in Honorem Eugenio Coseriu, Tubinga: Gunter Narr, vol. 1, 327-364.

Coseriu, Eugenio, 1988: Sincronía, diacronía e historia. El problema del cambio lingüístico, Madrid: Gredos.

Coseriu, Eugenio, 1990: “El español de América y la unidad del idioma”, I Simposio de Filología Iberoamericana (Sevilla, 26 al 30 de marzo de 1990), Zaragoza, Libros Pórtico, 43-75.

Coseriu, Eugenio, 2003: Geschichte der Sprachphilosophie. Von de Anfängen bis Rousseau. (Neu bearbeitet und erweitert von Jörn Albrecht. Mit einer Vor-Bemerkung von Jürgen Trabant), Tubinga/Basilea: A. Francke.

Coseriu, Eugenio, 2007a: Lingüística del texto. Introducción a la hermenéutica del sentido (edición, anotación y estudio previo de Óscar Loureda LAmAs), Madrid: Arco/Libros.

Coseriu, Eugenio, 2007b: Il linguaggio e l'uomo attuale. Saggi di filosofia del linguaggio. Traducción y edición de Cristian Bota y Massimo Schiavı, con la colaboración de Giuseppe Dı Salvatore y Lidia Gasperonı, Verona: Edizioni Fondazione Centro Studi Campostrini.

Coseriu, Eugenio, 2015: Geschichte der Sprachphilosophie. Band 2. Von Herder bis Humboldt. (Neu bearbeitet und herausgegeben von Jörn Albrecht), Tubinga: Narr Francke Attempto Verlag.

DiéGuez Lucena, Antonio, 2005: Filosofía de la ciencia, Madrid/Málaga: Biblioteca Nueva / Servicio de Publicaciones e Intercambio Científico de la Universidad de Málaga.

Diez, José A., y Carlos Ulises Moulines, 1999: Fundamentos de filosofía de la ciencia, BarceIona: Ariel.

ECheverRía, Javier, 1999: Introducción a la metodología de la ciencia. La filosofía de la ciencia en el siglo XX, Madrid: Cátedra.

Estany, Anna, 1993: Introducción a la Filosofía de la Ciencia, Barcelona: Crítica.

Fernández Pérez, Milagros, 1984: “El carácter de la ciencia lingüística”, Verba 11, 129-156.

Fernández Pérez, Milagros, 1985: "A propósito del libro de E. Itkonen, Causality in Linguistic Theory, London, Croom Helm, 1983, 332 pp.", Verba 12, 399-410.

Fernandez Pérez, Milagros, 1986: La investigación lingüística desde la Filosofía de la Ciencia (A propósito de la lingüística chomskiana), Santiago de Compostela: Universidad (Verba. Anuario Galego de Filoloxia, Anexo 28). 
Fernández Pérez, Milagros, 1993: "Sociolingüística y Lingüística”, Lingüística Española Actual XV (2), 149-248.

Fernández Pérez, Milagros, 1999: Introducción a la Lingüística. Dimensiones del lenguaje y vías de estudio, Barcelona: Ariel.

HABER, Gerda, 2015: "La relation entre la philosophie du langage et la sémantique chez Coseriu” en Christoph Gérard y Régis Missire (eds.): Eugenio Coseriu aujour d'hui. Linguistique et philosophie du langage, Limoges: Lambert-Lucas, 21-34.

Hammarström, Göran, 2013-14: "Causality and intentionality in the explanation of diachronic linguistics", Energeia. Online Zeitschrift für Sprachwissenschaft und Sprachphilosophie 5 [www. energia-online.de], 1-14.

Hempel, Carl G., y Paul Oppenheim, 1948: "Studies in the Logic of Explanation", Philosophy of Science $15,135-175$.

ITKonen, Esa, 1970: "An epistemological approach to linguistic semantics", Ajatus: The Yearbook of the Philosophical Society of Finland XXXII, 96-142.

ITKonen, Esa, 1974: Linguistics and Metascience, Kokemäki: Risteen kirjapaino.

ITKonen, Esa, 1975: Concerning the relationship between linguistics and logic, Indiana: The Indiana University Linguistics Club.

ITKONEN, Esa, 1976a: "The use and misuse of axiomatics in linguistics", Lingua 38 (3-4), 185-410.

ITKONEN, Esa, 1976b: Linguistics and empiricalness: answers to criticisms, Helsinki: Publications of the General Linguistics Department of the University of Helsinki.

ITKONEn, Esa, 1976c: "Was für eine Wissenschaft ist die Linguistik eigentlich?” en Dieter WunderцІсн (ed.): Wissenschaftstheorie der Linguistik, Frankfurt a. M.: Athenäum, 56-76.

ITKonen, Esa, 1978: Grammatical Theory and Metascience: A critical investigation into the methodological and philosophical foundations of 'autonomous' linguistics, Ámsterdam: John Benjamins.

ItKonen, Esa, 1980: "Qualitative vs. quantitative analysis in linguistics" en Thomas A. PerRy (ed.): Evidence and argumentation in linguistics, Berlín: De Gruyter, 334-366.

ItKonen, Esa, 1981a: "Rationality as an explanatory principle in linguistics" en Horst GeCKeler y otros (eds.): Logos semantikos: studia in honorem Eugenio Coseriu 1921-1981, Berlín / Nueva York / Madrid: Walter de Gruyter / Gredos, vol. II (ed. por Harald WEYDT): Sprachtheorie und Sprachphilosophie / Teoría y Filosofía del Lenguaje, 77-87.

ITKOnEn, Esa, 1981b: "The concept of linguistic intuition" en Florian Coulmas (ed.): A festschrift for native speaker, La Haya: Mouton, 127-140. 
ItKonen, Esa, 1983: Causality in Linguistic Theory: A critical investigation into the methodological and philosophical foundations of 'non-autonomous' linguistics, Londres: Croom Helm.

ItKonen, Esa, 1984: "On the 'rationalist' conception of linguistic change”, Diachronica I (2), 203-216.

ItKonen, Esa, 1993: "Hermeneutics” en Ron E. Asher (ed.): The encyclopedia of language and linguistics, Oxford: Pergamon Press, 1544-1545.

ITKOnEn, Esa, 1996: “Concerning the generative paradigm”, Journal of Pragmatics 25, 471-501.

ITKonen, Esa, 1997: "The social ontology of linguistic meaning", SKY: The Yearbook of the Linguistic Association of Finnland 10, 49-80.

ITKonen, Esa, 1999a: "A comment on András Kertész, 1998: 'Metalinguistic als Forschungsprogramm'”, Sprachtheorie und Germanistische Linguistik 8 (2), 133-176.

ITKOnEN, Esa, 1999b: "Functionalism yes, biologism no: a comment on Haspelmath 1999", Zeitschrift für Sprachwissenschaft 18 (II), 219-221.

ITKONEn, ESa, 2002a: "Linguistics as a system of distinct types of ontology-cum-epistemology" en Peter Gärdenfors y otros (eds.): In the scope of logic, methodology and philosophy of science. IIth International Congress of Logic, Methodology and Philosophy of Science (Cracovia, agosto de 1999), Dordrecht: Kluwer, vol. II, 431-441.

ITKONEN, Esa, 2002b: "Grammaticalization as an analogue of hypothetico-deductive thinking", en Ilse Wischer y Gabriele Diewald (eds.): New Reflections on Grammaticalization, Ámsterdam: John Benjamins, 413-422.

ITKonen, Esa, 2002c: "Einfühlung ('re-enactment') as the basic method of typological linguistics”, Puhe ja kieli/Speech and language 22 (4), 151-162.

ITKONEn, Esa, 2003: Methods of formalization beside and inside both autonomous and nonautonomous linguistics, Turku: Universidad de Turku.

ITKonen, Esa, 2003 [2008]: ¿Qué es el lenguaje? Introducción a la Filosofía de la Lingüística. Madrid: Biblioteca Nueva. Introducción, versión española y notas de Araceli López SeREnA del original inglés What is Language? A Study in the Philosophy of Linguistics, Turku: University of Turku, 2003.

ITKonen, Esa, 2011: "On Coseriu’s legacy”, Energeia. Online Zeitschrift für Sprachwissenschaft und Sprachphilosophie 3, 1-29 [www.energia-online.de].

ITKOnEn, Esa, 2013-2014: "On explanation in linguistics", Energeia. Online Zeitschrift für Sprachwissenschaft und Sprachphilosophie 5, 10-40 [www.energia-online.de]. 
Jiménez Ruiz, José Luis, 2006: Metodología de la investigación lingüística, Alicante: Publicaciones de la Universidad de Alicante.

Kabatek, Johannes, 2016: "Zur Gegenwart und Zukunft der Linguistik Eugenio Coserius" en Vicenzo Orioles y Raffaela Bombi (eds.): Oltre Saussure. L'eredità scientifica di Eugenio Coseriu / Beyond Saussure. Coseriu's scientific legacy, Florencia: Franco Cesati, $71-73$ [http://www.rose. uzh.ch/dam/jcr:ca40c9ec-d64d-46c6-8800-63C44f5b40f7/C101.pdf].

KaBATEK, Johannes, 2019: "Linguistic Norm in the Linguistic Theory of Eugenio Coseriu" en Franz LeBSANFt y Felix TACKE (eds.): Manual of Standardization in the Romance Languages, Berlín: De Gruyter Mouton, 127-144.

Kabatek, Johannes, y Adolfo Murguía, 1997: „Die Sachen sagen, wie sie sind.... Eugenio Coseriu im Gespräch, Tubinga: Gunter Narr.

Koch, Peter (1988): "Norm und Sprache" en Jörn AlbreCht, Jens Lüdtke y Harald Thun (eds.): Energeia und Ergon. Studia in Honorem Eugenio Coseriu, Tubinga: Gunter Narr, vol. II, 327-354.

López Serena, Araceli, 2003: "Algunos aspectos epistemológicos de la lingüística contemporánea”, Res Diachronicae 2, 212-220 [https://www.ucm.es/data/cont/media/www/pag-55536/ articulo_lópez_serena.pdf].

López Serena, Araceli, 2007: “Invitación a la epistemología lingüística. A propósito de Jesús Gerardo Martínez del Castillo, Los fundamentos de la teoría de Chomsky. Revisión Crítica. Madrid: Biblioteca Nueva, 2006 (Estudios críticos de literatura)", Verba 34, 444-454.

López Serena, Araceli, 2008: “Introducción: La Filosofía de la Lingüística de Esa Itkonen: hermenéutica frente a monismo metodológico”, en Esa ITKONEN, 2003 [2008], 13-31.

López Serena, Araceli, 2009: “Eugenio Coseriu y Esa Itkonen: Lecciones de filosofía de la lingüística”, Energeia. Online Zeitschrift für Sprachwissenschaft und Sprachphilosophie 1, 1-49 [www. energia-online.de].

López Serena, Araceli, 2011: “¿Es empírico el estudio de la (des)cortesía verbal? El estatus epistemológico de la lingüística de la (des)cortesía” en Catalina Fuentes, Esperanza Alcaide y Ester BreNES (coords.): Aproximaciones a la (des)cortesía verbal en español, Berna: Peter Lang, 425-442

López Serena, Araceli, 2014a: "Selección natural, explicación racional y cambio lingüístico: Hacia una fundamentación epistemológica no evolucionista de la teoría de la gramaticalización”, Rilce 30 (3), 724-775.

López Serena, Araceli, 2014b: “Historia de la lengua e intuición. Presentación”, Rilce 30 (3), 691-704.

López Serena, Araceli, 2015: "La tensión entre teoría y norma en la Nueva gramática de la lengua española. Una falsa disyuntiva epistemológica”, BRAE tomo XCV, cuaderno CCCXI (enero-junio 2015), 143-166. 
López Serena, Araceli, 2016: "El establecimiento de niveles y unidades en el análisis del discurso. Una primera aproximación metateórica” en Araceli López Serena, Antonio Narbona Jiménez y Santiago del Rey Quesada (dirs.): El español a través del tiempo. Estudios ofrecidos a Rafael Cano Aguilar, Sevilla: Editorial Universidad de Sevilla, vol. II, 1152-1175.

López Serena, Araceli, 2019: La lingüística como ciencia humana. Una incursión desde la filosofía de la ciencia, Madrid: Arco/Libros.

Loureda Lamas, Óscar, 2007: "Presentación del editor: Ia Textlinguistik de Eugenio Coseriu", en Eugenio Coseriu, 2007, 19-81.

Marti Sanchez, Manuel, 1993: "Acerca de la relación entre la lingüística y su atmósfera filosófica y científica", Verba 20, 7-27.

Marti Sanchez, Manuel, 1998: En torno a la cientificidad de la Lingüística: Aspectos diacrónicos y sincrónicos, Alcalá de Henares: Universidad.

Méndez García de Paredes, Elena, 1999: “La norma idiomática del español: visión histórica”, Philologia Hispalensis XIII (I), 109-132

Moran, Dermot, 2000: Introduction to Phenomenology, Londres: Routledge.

Oesterreicher, Wulf, 1979: Sprachtheorie und Theorie der Sprachwissenschaft, Heidelberg: Carl Winter-Universität Verlag.

Pos, H.-J., 1939: "Phénomenologie et linguistique”, Revue Internationale de Philosophie I (2), 354-365.

Rodriguez, Fernando Gabriel, 2016: "La filosofía del lenguaje de Eugenio Coseriu a la luz de la investigación psicológica sobre formación de conceptos: acerca del lenguaje como sistema de coordenadas conceptuales básicas", Lengua y Habla 20, 72-95 [https://dialnet.unirioja.es/ descarga/articulo/5756916.pdf, fecha de consulta: 8 de diciembre de 2017].

Rosenberg, Alex, 2000: Philosophy of Science, Londres: UCL Press.

Ruiz Fernández, José, 2006: El sentido del conocimiento científico empírico y el problema de la racionalidad: una investigación fenomenológica, Madrid: Universidad Complutense de Madrid.

Winter-Froemel, Esme, 2013-14: "What does it mean to explain language change? Usage-based perspectives on causal and intentional approaches to linguistic diachrony, or: o S-curves, invisibles hands, and speaker creativity", Energeia. Online Zeitschrift für Sprachwissenschaft und Sprachphilosophie 5, 123-142 [www.energia-online.de].

Wunderlich, Dieter (ed.), 1976: Wissenschaftstheorie der Linguistik, Kronberg: Athenäum Verlag. 